\title{
Study on Status of Accounting Computerization Implementation and Its Future Trends
}

\author{
Juan Cheng ${ }^{1, a}$ \\ ${ }^{1}$ Nanchang Institute of Science \& Technology, Nanchang, Jiangxi, 330108 \\ a email
}

Keywords: Accounting, Implementation Status, Future Trends

\begin{abstract}
With the progress and development of science and technology, the scope of application of modern information technology more widely, computerized accounting gradually began to gain popularity. Accounting popularity not only allows accounting work efficiency and enhance the effective treatment, at the same time gradually become the current enterprise management process of economic development and an important tool. However, although the moment of a growing number of companies have come to realize the importance of computerized accounting, but due to the development of computerized accounting course is shorter, its implementation still exist many problems. In this paper, the current implementation of computerized accounting brief analysis of the current situation, and prospects for its future development on this basis, hoping to bring some help to the development of computerized accounting.
\end{abstract}

\section{Introduction}

In the current information age, background, computerized accounting gradually replaced the traditional manual accounting model so that accounting data collection, collation and analysis functions into full play, bringing great convenience for the modern enterprise information management and decision making steady . However, the practical implementation of computerized accounting, since its development process is shorter, resulting in its implementation process there are still many problems, contribution to development of computerized accounting caused a serious obstacle. To give effect to give full accounting information, it must be done on the importance of computerized accounting new understanding, and thus to make the implementation of the current plight of Accounting has been effectively resolved, promote the rapid development of computerized accounting.

\section{Analysis of the Status of Implementation of Computerized Accounting}

Accounting application mainly lies in the use of computers, which is the accounting knowledge and computer knowledge integration, so that the effectiveness of corporate finance and accounting management can be achieved. Therefore, the accounting staff which also need to be associated not only with professional accounting knowledge, and have a certain degree of computer application and practical knowledge. However, from the moment the process of computerized accounting practices, computerized accounting personnel to meet these two requirements are few and far. In China, traditional accounting management model mostly in the form of train an apprentice chef, and when computerized accounting management implementation, often lack the accounting staff will make some computer knowledge can not adapt, plus some accounting staff expertise the deficiencies, but also resulted in the implementation of computerized accounting and management accounting practice divorced from the phenomenon [1]. For just training up computerized accounting management personnel, although whether it is computer knowledge or expertise are in line with work standards, but because of the special nature of accounting work, not just with relevant expertise will be able to posts, which also requires the relevant managers have a high moral quality and comprehensive training and, therefore, increase the difficulty of computerized accounting personnel training.

On the current situation, the development of computerized accounting late, yet still kept in its 
infancy, it also resulted in many companies, whether in thought or in the concept, not a correct understanding of the accounting the importance and role of computerization. Accounting thus also resulted in the actual implementation process, some enterprises and units mostly just focus on how to make the administrative burden of accounting personnel is reduced, so that the efficiency of accounting accounting would be enhanced, and for Accounting Management Information System Construction the lack of proper understanding and attention and, thus prompting accounting accounting personnel management information feedback want timely and effective management of the enterprise displayed in front there is a certain degree of difficulty, and thus it is difficult to bring good to the development of enterprise development strategies service. Plus, the practical application of computerized accounting requires not only the relevant accounting personnel certain level of accounting expertise, but also need to be familiar with computer knowledge, the use of technology and financial software maintenance and repair.

\section{Measures to Improve Effective Computerized Accounting}

Computerized Accounting management in order to achieve the desired effect, it must have a sound internal control system. The focus on the implementation of internal control lies in the direction of the many important aspects of organizational structure, accounting records, the quality of workers and reporting system. Integrity of the internal system is mainly to show in their daily work and control all aspects of the program work. Various violations must be strict precautions, let's accounting practices be effectively guaranteed. In the process of financial accounting, we should distinguish between cash and other monetary funds, financial security system at work to focus on strengthening. In the accounting process, we need to do effective work processes clear, specific work to achieve effective implementation [2]. And in the financial supervision, to complete the evaluation system set up, so that regulatory functions into full play. In simple terms, it is to establish a system to regulate and improve them in order to clear responsibilities and clear, so that progress can be accelerated, so that the overall efficiency has been improved. Also, the financial accounting processes to achieve clear, for a person to do a post strictly enforced, so that staffing has been optimized, and regular assessment and evaluation of the relevant personnel.

First, it should be proactive to introduce computerized management and training of highly qualified accounting personnel, accounting for the overall quality of personnel were continuously strengthened, prompting capable of mastering the relevant operating methods and basic computer knowledge. But also attention from the professional quality and enhance the safety awareness of accounting personnel, thereby to allow computerized accounting information system security is improved. Secondly, the role of standardization in order to allow computerized accounting play, but also the knowledge structure should be continuous training of accounting personnel, and increase efforts to train personnel, and regularly carry out job training and learning, so that the relevant accounting Computing computer expertise and technical management personnel can be continuously improved.

\section{The Future Development Trend of Computerized Accounting}

In the process of enterprise management, internal accounting management has a very important effect on the operation and development of enterprises have a certain role in promoting. In order for the work to be further strengthened internal accounting, accounting responsibility should be based on the use of targeted methods of internal control system for continuous efforts to strengthen and promote the smooth implementation of the work. Modern enterprise system to build and improve, not only for business operation has a great help, but also to enhance their market competitiveness. Especially the internal management, such as asset, financial and cost management. In order to enhance internal management efficiency, promote the implementation of the internal management of modern enterprises are usually more emphasis on profits and cost targets, by the corresponding target responsibility system set up so that each unit and staff functions have been implemented, and the aid assessment work for reward and punishment, prompting management objectives can be 
effectively realized [3]. In addition, also improve the internal management of enterprises to some extent in other work and, thus, to promote the work of accounting supervision has been further strengthened, while a great role in promoting institutional development that work brings. The modern enterprise, it increasingly began to focus on its role and is gradually on the internal accounting supervision system for continuous improvement, also made accounting norms. Moreover, many companies began to relations audit, securities supervision departments to re-understanding and treatment, thereby to allow the internal management has been strengthened, so that the work to develop flowers, standardization can be achieved gradually.

Accounting system is an organic whole, it has a certain complexity, which is mainly a combination of a plurality of links and the role of each other factors. And accounting system also has a closed and open these two conflicting characteristics, so many factors will impact on the operation of the accounting system, such as internal factors, external factors. Therefore, should pay attention to the modern enterprise management system from working, should actively use targeted measures, the overall management of the entire accounting system. In addition, the accounting system also has some differences, but also to have a lot of different subsystems, in order to allow management level to enhance and promote the good operation and development of enterprises, it is necessary to carry out the management subsystem continuously strengthened. For example: the use of appropriate measures to effectively control costs, and the rational allocation and use of funds [4]. In addition, different management conditions, will form a difference management processes and content to facilitate the gradual emergence of a different management systems, such as accounting forecasting, decision-making and control, and gradually the entire Metro rows accounting management system. In actual operation, should also be strengthened every aspect of management, process management and systematic work.

\section{Conclusion}

All in all, under the background of the current information age, technology, and many other factors that influence the development of modern accounting information to make China gradually takes on a new trend, but also to the formation of computerized accounting accounting management efficiency and quality have been effectively promotion. Therefore, Chinese enterprises only to the status of implementation of accounting electronic comprehensive analysis to identify the targeted improvement measures, and from the internal management and systems management computerized accounting management, and promote long-term development of computerized accounting .

\section{Acknowledgements}

Fund projects: university reform project, Integrated multi-disciplinary research on ERP Practice Teaching school-enterprise collaboration and innovation and entrepreneurship Ability.

Item Number: NGJG-2015-13.

\section{References}

[1] Ma Jingbin. In the present letter Status of Accounting and future trends [J]. industrial accounting, 2012, 02: 26-27.

[2] Chen Xiangxi. of computerized accounting problems and future development trend of China's current [J]. Market Modernization, 2014,02: 328-329.

[3] Hu Wei. Situation and Development Trend of Accounting Computerization - A Case Study of SMEs [J]. China Science and Technology Information, 2012, 22: 137-138.

[4]Wang Jinyan. Application Status and Development Trend of Coal Enterprises Accounting Research [J]. Business Economics, 2013, 24: 106-107. 